\title{
Diacenaphthylene-fused benzo[1,2-b:4,5- b']dithiophenes: polycyclic heteroacenes containing full-carbon five-membered aromatic rings
}

Article

Accepted Version

Wu, H., Fang, R., Tao, J., Wang, D., Qiao, X., Yang, X., Hartl, F. and Li, H. (2017) Diacenaphthylene-fused benzo[1,2-b:4,5$b^{\prime}$ ']dithiophenes: polycyclic heteroacenes containing full-carbon five-membered aromatic rings. Chemical Communications, 53 (4). pp. 751-754. ISSN 1364-548X doi: https://doi.org/10.1039/C6CC09184A Available at https://centaur.reading.ac.uk/68369/

It is advisable to refer to the publisher's version if you intend to cite from the work. See Guidance on citing.

To link to this article DOI: http://dx.doi.org/10.1039/C6CC09184A

Publisher: The Royal Society of Chemistry

All outputs in CentAUR are protected by Intellectual Property Rights law, including copyright law. Copyright and IPR is retained by the creators or other copyright holders. Terms and conditions for use of this material are defined in the End User Agreement. 


\section{www.reading.ac.uk/centaur}

\section{CentAUR}

Central Archive at the University of Reading

Reading's research outputs online 


\section{Accepted Manuscript}

This article can be cited before page numbers have been issued, to do this please use: H. Wu, R. Fang, J.

Tao, D. Wu, X. Qiao, X. Yang, F. Hartl and H. Li, Chem. Commun., 2016, DOI: 10.1039/C6CC09184A.
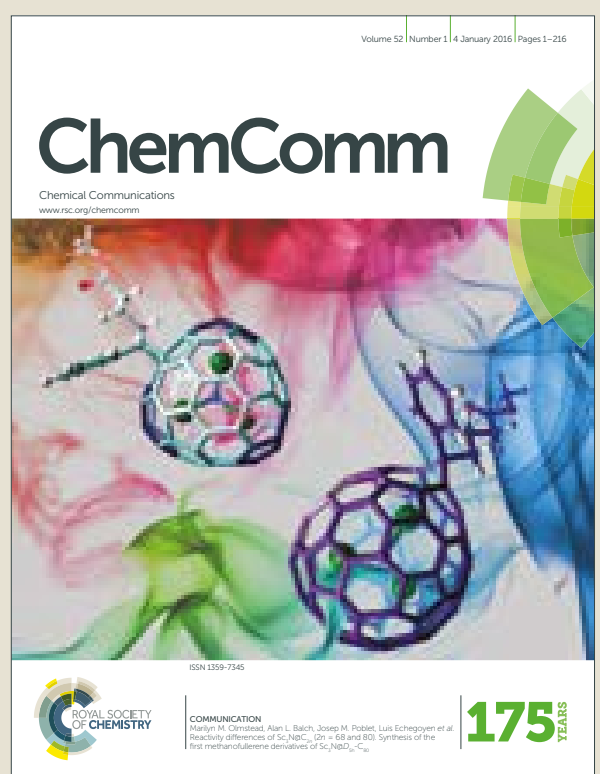

This is an Accepted Manuscript, which has been through the Royal Society of Chemistry peer review process and has been accepted for publication.

Accepted Manuscripts are published online shortly after acceptance, before technical editing, formatting and proof reading. Using this free service, authors can make their results available to the community, in citable form, before we publish the edited article. We will replace this Accepted Manuscript with the edited and formatted Advance Article as soon as it is available.

You can find more information about Accepted Manuscripts in the author guidelines.

Please note that technical editing may introduce minor changes to the text and/or graphics, which may alter content. The journal's standard Terms \& Conditions and the ethical guidelines, outlined in our author and reviewer resource centre, still apply. In no event shall the Royal Society of Chemistry be held responsible for any errors or omissions in this Accepted Manuscript or any consequences arising from the use of any information it contains. 
Received 00th January 20xx, Accepted 00th January 20xx

DOI: $10.1039 / \times 0 \times x 00000 x$

\section{Diacenaphthylene-Fused Benzo[1,2-b:4,5-b']dithiophenes: Polycyclic Heteroacenes Containing Full-Carbon Five-Membered Aromatic Rings}

\author{
Hongzhuo $\mathrm{Wu}^{a}$, Renren Fang ${ }^{a}$, Jingwei Tao ${ }^{a}$, Deliang Wang ${ }^{a}$, Xiaolan Qiao ${ }^{a}$, Xiaodi Yang ${ }^{c}$ *,
} František Hartl ${ }^{b, *}$, Hongxiang $\mathrm{Li}^{a, *}$

www.rsc.org/

We herein report on an efficient synthesis of diacenaphthylenefused benzo[1,2-b:4,5-b']dithiphenes and demonstrate that their packing structure in the solid state depends on the substituent groups. These compounds form dimers with their radical cations in high solution concentration and display good field-effect mobility.

Polycyclic aromatic compounds (PACs) are of great interest because of their unique electronic structures and physical properties, and wide applications as functional materials. ${ }^{1-4}$ PACs are usually composed of six-membered benzene rings and/or five-membered heteroaromatic rings (such as thiophene, pyrrole and furan). ${ }^{5-7}$ A full-carbon five-membered aromatic ring is an analogue of five-membered heteroaromatic rings and a building block of fullerenes. Recently, planar cyclopenta-fused polycyclic arenes (such as acenaphthylenes, dibenzopentalenes and indenofluorenes) featuring full-carbon five-membered anti-aromatic rings, have intensely been investigated. ${ }^{11-15}$ However, planar PACs containing full-carbon five-membered aromatic rings (FC-PACs) are rarely reported, even though some of them display special self-assembly properties, good transistor and solar cell performance, and biradical characteristics. ${ }^{8-12}$ Hence it is of great importance and general interest to synthesize new type of FC-PACs and explore their fundamental properties as well as practical applications. Currently, the synthetic strategies to FC-PACs are limited and remain challenging, usually involving tedious synthetic steps and/or poor reaction scope. Herein, with Pd-catalyzed $\mathrm{C}-\mathrm{H}$ activation reaction, we report on a facile synthesis of nine-ring fused planar FC-PACs, diacenaphthylene fused benzo[1,2b:4,5-b'] dithiophenes M2-M6 (Scheme 1).

\footnotetext{
a. Shanghai Institute of Organic Chemistry, Chinese Academy of Sciences, Shanghai, 200032, China.E-mail:Ihx@mail.sioc.ac.cn

${ }^{b}$ Department of Chemistry, University of Reading, Whiteknights, Reading RG6 6AD, United Kingdom.E-mail: f.hartl@reading.ac.uk

c. Laboratory of Advanced Materials, Fudan Univeristy, Shanghai, 200438, China. Email: yangxiaodi@fudan.edu.cn

Electronic Supplementary Information (ESI) available: [Synthetic procedure and compound characterizations, electrochemistry result, single crystal CIF files]. See DOI: $10.1039 / \times 0 \times x 00000 x$
}

There has been a growing interest in dimerization of $\pi$ conjugated molecules and their radical cations studied with a dual purpose, viz. (i) understanding the nature of the chargetransport phenomena in p-doped organic semiconductors, and (ii) potential application of these compounds in material science and supramolecular chemistry, such as switches, molecular motors, data storage systems and so on. ${ }^{16-18}$ Interestingly, planar rigid FC-PACs M2-M6 display rich redox behavior and form dimers with their radical cations at high solution concentration, being confirmed with solution dependent differential pulse voltammogram (DPV) and spectroelectrochemistry. The application of CF-PACs as semiconductors in transistors was also investigated.

Table 1. Pd-catalyzed $\mathrm{C}-\mathrm{H}$ activation reaction of benzo[b]thiophene with $1,8-$ dibromonaphthalene.
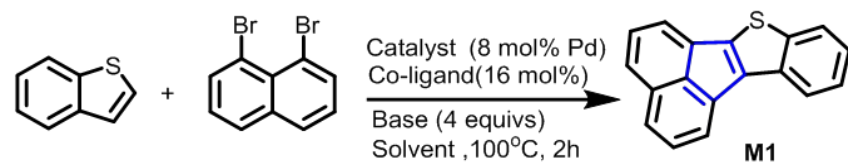

\begin{tabular}{cccccc}
\hline Entry & Catalyst & Co-ligand & Base & Solvent & Yield [a] \\
\hline 1 & $\mathrm{Pd}(\mathrm{OAc})_{2}$ & $\mathrm{P}(\mathrm{t}-\mathrm{Bu})_{2} \mathrm{Me} \cdot \mathrm{HBF}_{4}$ & $\mathrm{KOAC}$ & $\mathrm{DMA}$ & $35.7 \%$ \\
2 & $\mathrm{Pd}(\mathrm{OAc})_{2}$ & $\mathrm{P}(\mathrm{t}-\mathrm{Bu})_{2} \mathrm{Me} \cdot \mathrm{HBF}_{4}$ & $\mathrm{~K}_{2} \mathrm{CO}_{3}$ & $\mathrm{DMA}$ & $68.7 \%$ \\
3 & $\mathrm{Pd}(\mathrm{OAC})_{2}$ & $\mathrm{P}(\mathrm{t}-\mathrm{Bu})_{2} \mathrm{Me} \cdot \mathrm{HBF}_{4}$ & $\mathrm{Cs}_{2} \mathrm{CO}_{3}$ & $\mathrm{DMA}$ & $11.9 \%$ \\
4 & $\mathrm{Pd}_{2}(\mathrm{dba})_{3}$ & $\mathrm{P}(\mathrm{t}-\mathrm{Bu})_{2} \mathrm{Me} \cdot \mathrm{HBF}_{4}$ & $\mathrm{KOAC}$ & $\mathrm{DMA}$ & $30.1 \%$ \\
5 & $\mathrm{Pd}(\mathrm{PPh})_{2} \mathrm{Cl}_{2}$ & $\mathrm{P}(\mathrm{t}-\mathrm{Bu})_{2} \mathrm{Me} \cdot \mathrm{HBF}_{4}$ & $\mathrm{KOAC}$ & $\mathrm{DMA}$ & $30.1 \%$ \\
6 & $\mathrm{Pd}(\mathrm{OAc})_{2}$ & $\mathrm{P}(\mathrm{t}-\mathrm{Bu})_{2} \mathrm{Me} \cdot \mathrm{HBF}_{4}$ & $\mathrm{KOAC}$ & toluene & 0 \\
7 & $\mathrm{Pd}(\mathrm{OAC})_{2}$ & $\mathrm{P}(\mathrm{t}-\mathrm{Bu})_{2} \mathrm{Me} \cdot \mathrm{HBF}_{4}$ & $\mathrm{KOAC}$ & dioxane & 0 \\
8 & $\mathrm{Pd}(\mathrm{OAC})_{2}$ & $\mathrm{P}(\mathrm{Cy})_{3} \cdot \mathrm{HBF}_{4}$ & $\mathrm{KOAC}$ & $\mathrm{DMA}$ & $7.1 \%$ \\
9 & $\mathrm{Pd}(\mathrm{OAc})_{2}$ & $\mathrm{P}(\mathrm{o}-\mathrm{tolyl})_{3}$ & $\mathrm{KOAC}$ & $\mathrm{DMA}$ & $6.3 \%$ \\
\hline
\end{tabular}

${ }^{[a]}$ Yield of isolated product

To explore the application of catalyzed $\mathrm{C}-\mathrm{H}$ activation reactions for the syntheses of CF-PACs, benzo[b]thiophene and 1,8-dibromonaphthalene were first used as model substrates (Table 1). The co-ligand, base and solvent were found to strongly affect the reaction yield; the optimum conditions were using $\mathrm{Pd}(\mathrm{OAc})_{2}$ as the catalyst, $\mathrm{P}(t-\mathrm{Bu})_{2} \mathrm{Me} \cdot \mathrm{HBF}_{4}$ as the co-ligand and $\mathrm{K}_{2} \mathrm{CO}_{3}$ as the base in DMA at $100^{\circ} \mathrm{C}$ (Table 1, 
entry 2 ). When benzo[b]thiophene was replaced by the larger conjugated benzo[1,2-b:4,5- $\left.b^{\prime}\right]$-dithiophene derivatives, the common organic semiconductor building blocks, nine-ring fused CF-PACS M2-M4 with two aromatic full-carbon fivemembered rings were synthesized in a one-pot step (Scheme 1). ${ }^{19}$ By changing the alkyl chains to more electron-donating alkoxy chains, the reactions worked well. When electrondeficient benzo[1,2- $b: 4,5-b^{\prime}$ ] dithiophene-4,8-dione was reacted with 1,8-dibromonaphthalene under the above conditions, compound M5 was obtained as an insoluble gray powder in $90 \%$ yield. Compound M5 further reacted with 5ethynyl-1,3-di(t-butyl)benzene, having afforded soluble and larger $\pi$-conjugated compound M6. The above results demonstrate the successful applications of a $\mathrm{C}-\mathrm{H}$ activation reaction in the preparation of CF-PACs.
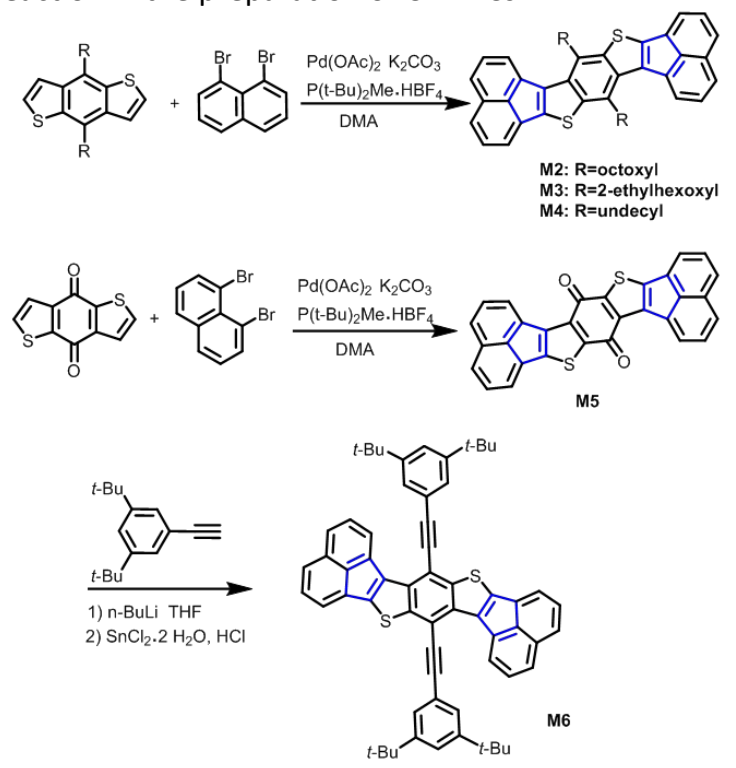

Scheme 1. Syntheses and chemical structures of CF-PACs M2-M6.

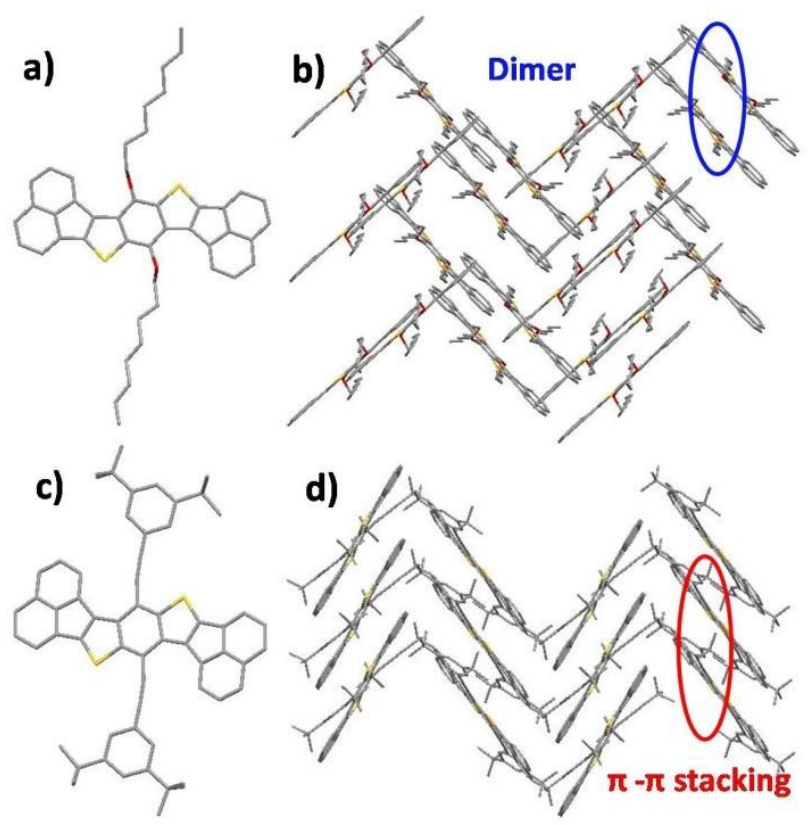

Figure 1. Crystal and packing structures of $\mathbf{M} 2(a-b)$ and $\mathbf{M 6}$ (c-d).
Single crystals of $\mathbf{M} 2$ and $\mathbf{M 6}$ were grow/mcle from dichloromethane / hexane using the DSolveht39evapopation method (Figure 1). The XRD data show that $\mathbf{M} 2$ belongs to a triclinic space group $\mathrm{P}-1$, with the cell parameters $\mathrm{a}=$ $13.0940(7) \AA, b=14.5388(8) \AA, c=20.6868(12) \AA, \alpha=$ $76.383(2)^{\circ}, \beta=82.5890(10)^{\circ}$ and $\gamma=80.352(2)^{\circ}$. In the single crystal, the conjugated core exhibits a planar structure, and the side chains are positioned out of the plane. Molecules of M2 form dimers in the crystals. Strong $\pi-\pi$ interactions with an interplane distance of $3.459 \AA$ and hydrogen bonds between $\mathrm{O}$ of the alkoxy substituent and $\mathrm{H}$ of the alkyl chain are observed in the dimers. $\mathrm{C}-\mathrm{H} . . . \pi$ interactions are encountered between the dimers. Similar to $\mathbf{M} \mathbf{2}$, the conjugated core of $\mathbf{M} \mathbf{6}$ shows a planar structure and the phenyl ring of the phenylacetylene substituent is out of the plane. However, the packing structure of $\mathbf{M 6}$ is different from that of M2. The single crystals of M6 belong to a monoclinic space group $\mathrm{C} 2 / \mathrm{c}$, with the cell parameters $a=41.379(8) \AA, b=6.0824(12) \AA, c=20.059(4) \AA$ and $\beta=106.27(3)^{\circ}$. M6 adopts a typical herringbone structure in the crystal, and slipped $\pi-\pi$ stacking with a distance of 3.426 $\AA$ is observed. Moreover, $\mathrm{C}-\mathrm{H} . . . \pi$ interactions between the conjugated cores exist for adjacent $\pi-\pi$ stackings. Unlike $\mathbf{M 2}$, the slipped $\pi-\pi$ stacking structure of $\mathbf{M 6}$ facilitates charge carrier transport and suggests its potential application as a semiconductor in organic transistors.

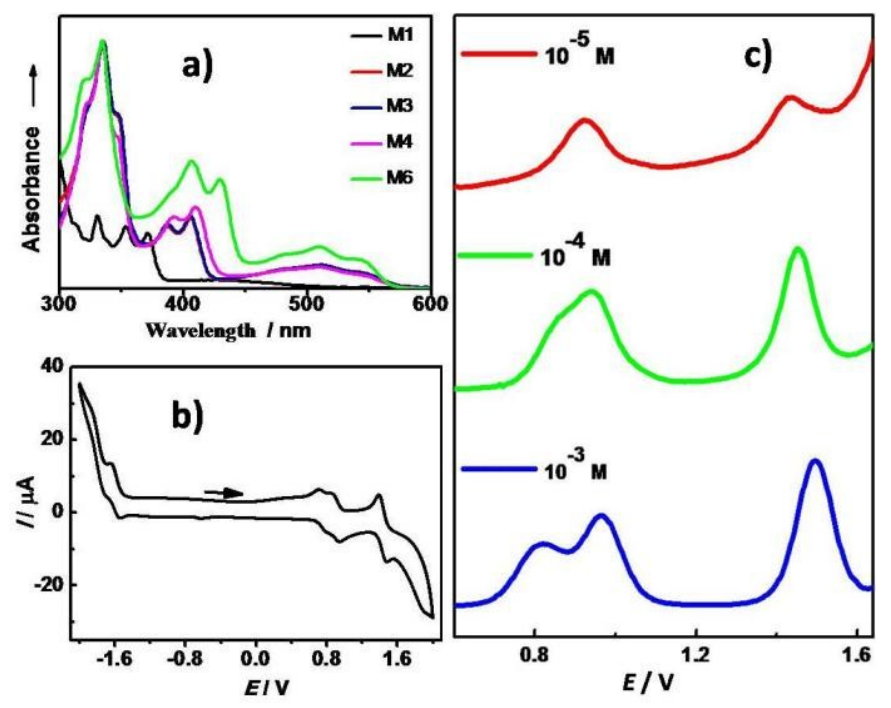

Figure 2. a) UV-vis absorption spectra of $\mathbf{M} 1-\mathbf{M} 4$ and $\mathbf{M 6}$ in $\mathrm{CH}_{2} \mathrm{Cl}_{2}$. b) Cyclic voltammogram (CV) of $\mathbf{M} 4\left(10^{-3} \mathrm{M}\right)$. c) Differential pulse voltammograms (DPV) of M4 at different concentrations. The $\mathrm{CV}$ s and DPVs were measured in $\mathrm{CH}_{2} \mathrm{Cl}_{2}$ solutions, using $10^{-1} \mathrm{Mn}-\mathrm{Bu}_{4} \mathrm{PF}_{6}$ as the supporting electrolyte, and SCE as the reference at the scan rate $v=100 \mathrm{mV} \mathrm{s}^{-1}$.

The electronic absorption spectra of M1-M4 and M6 in $\mathrm{CH}_{2} \mathrm{Cl}_{2}$ are shown in Figure 2a. All compounds absorb in the range of $300-600 \mathrm{~nm}$. Compared to $\mathbf{M 1}$, the onset of the lowlying structured absorption bands of $\mathbf{M 2 - M 6}$ is strongly bathochromically shifted by ca $4500 \mathrm{~cm}^{-1}(0.55 \mathrm{eV})$, which nicely agrees with the smaller HOMO-LUMO gap determined by cyclic voltammetry (Figure $2 \mathrm{~b}$ and Figure S2, Supporting Information), see below. This difference is ascribed to the increased conjugation length of M2-M4 and M6 that have very 
similar electronic absorption spectra, with two vibronically structured absorption bands at ca 400 and $500 \mathrm{~nm}$. The former absorptions are slightly red-shifted in the order of alkyl <alkoxy< phenylacetylene, likely because of the increased electron-donating nature of the substituents and the enlarged conjugation structures.

The redox properties of M1-M4 and M6 were first investigated by cyclic voltammetry (CV) in dichloromethane (Figure $2 \mathrm{~b}$ and Figure S2 in Supporting Information). M1 displays in the available potential window only one reversible electron oxidation and one reversible reduction near the electrolyte limits. Both processes exhibit similar peak currents, in line with their reversible nature. Interestingly, M2-M4 and M6 show richer redox chemistry, with two cathodic and three anodic steps observable at the concentration of $10^{-3} \mathrm{M}$. Importantly, the first two anodic steps are closely spaced and their peak currents reach ca. one half of the peak currents for the first cathodic wave and the third anodic wave. The corresponding DPV measurements with M4, selected for a detailed study, have shown that the first and second anodic waves fuse gradually with decreasing the concentration of the compound. For $10^{-5} \mathrm{M} \mathrm{M4}$, only two anodic peaks with equal current intensities are observed at room temperature (Figure $2 b)$. This concentration dependence indicates the formation of dimers between $\mathbf{M} \mathbf{4}$ and its radical cation, [M4-M4] $]^{+}$, at sufficiently high concentrations. ${ }^{18,20}$ This explanation is supported by the dominant localization of the initial anodic step on the central benzodithiophene part (Figure S1, Supporting Information - the unsubstituted model of M4). The oxidation potential of the non-oxidized half of the cationic dimer then becomes slightly positively shifted. Apparently, doubly oxidized dimer $[\mathbf{M} 4-\mathbf{M} 4]^{2+}$ is unstable at ambient temperature and dissociates to $[\mathbf{M} 4]^{+}$radicals further oxidizing to $[\mathbf{M} 4]^{2+}$ at the electrode potential of the third, one-electron anodic wave. More support for this peculiar anodic behavior of M4 is given in the following spectroelectrochemical section.The redox potentials of M1-M4 and M6 are summarized in Table S1. M2-M4 and M6 have their HOMOLUMO band gap larger than $2.3 \mathrm{eV}$ and the HOMO energy levels at about $5.10-5.40 \mathrm{eV}$, suggesting their application as organic semiconductors in p-type organic transistors.

The redox behavior of undecyl-substituted compound M4, selected to represent the whole series, was monitored by in situ UV-vis-NIR spectroelectrochemistry (Figure 3; saturated solution in dichloromethane) in combination with thin-layer cyclic voltammetry within an OTTLE cell to confirm the stability of the redox products. $^{21}$ The reversible reduction of $\mathbf{M} 4$ to [M4] is accompanied by the growth of a broad absorption band at $720 \mathrm{~nm}$. The spectral changes accompanying the oxidation of $\mathbf{M 4}$ to [M4] ${ }^{+}$reveal that this process occurs in two separate steps, in accordance with the CV and DPV scans (Figure 2). Initially (at $0.7 \mathrm{~V}$ ), the intense sharp parent absorption at $320 \mathrm{~nm}$ drops to ca one half of the total absorbance and new absorption bands grow at 750 and 1000 $\mathrm{nm}$. The bifurcated parent absorption at $400 \mathrm{~nm}$ is still apparent in the resulting spectrum. Moving the anodic potential to the second anodic wave at $0.8 \mathrm{~V}$ causes further
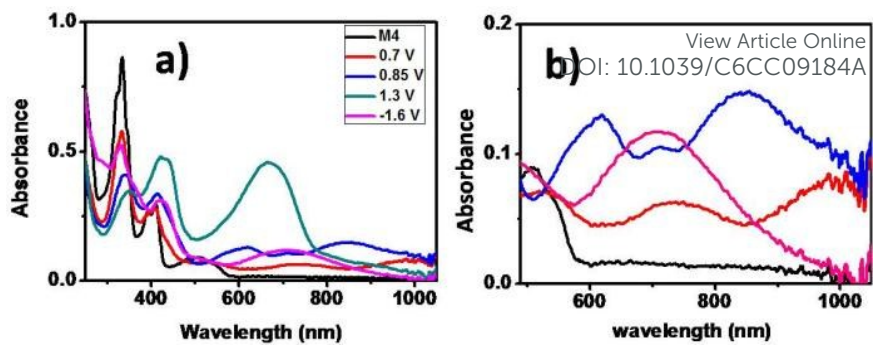

Figure 3. (a) The electronic absorption spectra of neutral M4 (black curve) in dichloromethane (the saturated solution at $293 \mathrm{~K}$ ) and its stable charged redox forms, viz. [M4] (purple curve), dimer [M4-M4] $]^{+}$(red curve), [M4] $]^{+}$(blue curve) and $[\mathbf{M}]^{2+}$ (turquoise curve). (b)The zoomed out spectral range of 500-1100 nm.
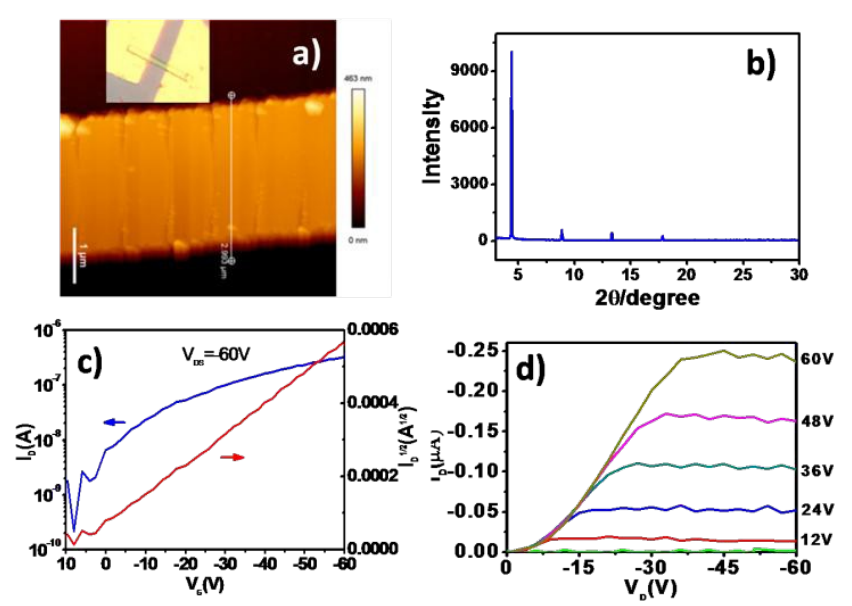

Figure 4. a) AFM image of the micro-/nano-sized wires of $\mathbf{M 6}$ deposited on the OTSmodified $\mathrm{Si} / \mathrm{SiO}_{2}$ substrates; (insert) the optical image of a micro-sized wire transistor. $\mathrm{b}$ ) XRD patterns of the micro-sized wires. c)-d) The transfer and output curves of M6 based microwire transistors.

decrease of the parent absorption at $320 \mathrm{~nm}$ and the bifurcated band at 400 disappears. In the visible-NIR region, however, new absorption bands grow at 600 and $860 \mathrm{~nm}$. These observations document that the parent absorption is preserved in the first anodic product, which can, therefore, be formulated as a half-oxidized dimer $[\mathbf{M} 4-\mathbf{M} 4]^{+}$. The $\mathbf{M} \mathbf{4}$ component of the dimer becomes oxidized at a more positive anodic potential due to its interaction with $[\mathbf{M} 4]^{+}$, probably via a $\pi$ bonding between the central benzodithiophene moieties constituting the HOMO of parent M4 (Figure S1). The existence of dimer [M4-M4] ${ }^{+}$also accounts for the splitting of the first anodic wave of $\mathbf{M} 4$ at increasing concentration $\left(>10^{-5} \mathrm{M}\right)$ into two waves exhibiting half peak currents compared to the first cathodic waves at $-1.59 \mathrm{~V}$ and the anodic wave at $1.30 \mathrm{~V}$. The latter probably corresponds to one-electron oxidation of monomer radical cation [M4] ${ }^{+}$formed by rapid dissociation of transient $[\mathbf{M} 4-\mathrm{M} 4]^{2+}$ generated at $0.8 \mathrm{~V}$. It needs to be appended that UV-vis-NIR spectroelectrochemistry with the OTTLE cell is insufficiently sensitive to monitor the direct oxidation of $10^{-5} \mathrm{M} \mathrm{M4}$ to the monomer radical cation indicated by DPV (Figure 2c) and thin-layer cyclic voltammetry. A detailed description of dimer [M4-M4 ${ }^{+}$with computational methods is out of scope of this work. 
Considering the HOMO energy level and the slipped $\pi-\pi$ stacking structure of $\mathbf{M 6}$, its application as an organic semiconductor was explored with field-effect transistor. Due to the strong self-assembly property, crystalline micro-/nanosized structures were obtained instead of continuous thin films after a solution of $\mathbf{M} \mathbf{6}$ had been deposited on a $\mathrm{SiO}_{2}$ substrate. After careful optimization, the micro-/nano-sized wires were prepared through drop casting a solution of $\mathbf{M 6}$ $\left(\mathrm{CH}_{2} \mathrm{Cl}_{2} /\right.$ petroleum ether $\left.4: 1, \mathrm{v} / \mathrm{v}\right)$ on an octadecyltrichlorosilane (OTS)-modified $\mathrm{SiO}_{2}$ substrate. The micro-sized wire transistors were fabricated in situ as bottomgate top-contact structure. The Au source and drain electrodes were fabricated through the "Au stripe mask" method. ${ }^{22}$ More than ten devices were measured, all of them having displayed a characteristic p-channel behavior. The electrical characterization of $\mathbf{M 6}$ revealed its good device performance with the mobility of $0.26 \mathrm{~cm}^{2} / \mathrm{Vs}$, that is one of the highest values measured for semiconductors based on FC-PACs.

To understand the measured field-effect mobility of M6, the morphology and packing structure of micro- / nano-sized wires were investigated through AFM and XRD. AFM images have shown that the wires have a rough surface with an RMS of $12.02 \mathrm{~nm}$. The length of the wires ranged between several micrometers and several tens of micrometers, and the width was several micrometers. Surprisingly, the thickness of the wires was larger than two hundred nanometers. Wires with such a large thickness are rarely reported in organic transistors because of the large resistance between the source/drain electrodes and the conducting channel of transistor. The attempts to explore the stacking structure of $\mathbf{M} \mathbf{6}$ in the wires with the selected area electron diffraction (SAED) technique failed.

Small-angle X-ray diffraction (XRD) has revealed that the wires are highly crystalline (Figure $4 \mathrm{~b}$ ). A series of peaks were observed at $4.46^{\circ}, 8.90^{\circ}, 13.33^{\circ}$ and $17.82^{\circ}$, belonging to the set of hoO diffractions according to the single crystal structure. The $d$-spacing estimated from the diffraction peaks is $19.895 \AA$. This value is very close to the $c$-axis length of compound M6 (20.059 $\AA$ ), indicating that $\mathbf{M 6}$ has the $c$ axis upright to the substrate in the micro-sized wires. With this orientation, the $\pi$ $\pi$ stacking direction is parallel to the substrate surface according to the single crystal structure, which facilitates the transport of charge carriers.

In summary, a facile synthetic procedure yielding planar FCPACs M2-M6 has been developed. Single crystal diffraction results have revealed that $\mathbf{M} \mathbf{2}$ forms dimers in the crystals, while slipped $\pi-\pi$ stacking was observed in the crystal structure of M6. M2 - M4 and M6 exhibit rich redox chemistry, forming a semi-oxidized dimer with their radical cations at high solution concentrations. The micro-sized wire transistors of M6 showed a good transistor performance with a hole mobility of $0.26 \mathrm{~cm}^{2} / \mathrm{Vs}$. All these results, together with a few reports on planar FC-PACs, have documented the potential of full-carbon five-membered aromatic ring-fused compounds for applications as functional materials.

This work was supported by the National Natural Sciences Foundation of China (Projects 21190031, 51273212) and the
"Strategic Priority Research Program" of the Chinese Acadermy

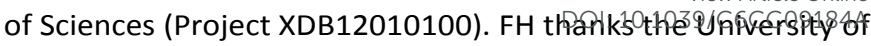
Reading for the continued support of the Spectroelectrochemistry Reading laboratories (Project D14015).

\section{Notes and references}

1 J. H. Dou, Y. Q. Zheng, Z. F. Yao, Z. A. Yu, T. Lei, X. X. Shen, X. Y. Luo, J. L. Sun, S.D. Zhang, Y. F. Ding, G. C. Han, Y. P. Yi, J. Y. Wang and J. Pei, J. Am. Chem. Soc., 2015, 137, 15947

2 N. J. Zhou, A. S. Dudnik, T. I. N. G. Li, E. F. Manley, T. J. Aldrich, P. J. Guo, H. C. Liao, Z. H. Chen, L. X. Chen, R. P. H. Chang, A. Facchetti, M. O. D. L. Cruz and T. J. Marks, J. Am. Chem. Soc., 2016, 138, 1240

3 I. Yavuz, B. N. Martin, J. Y. Park and K. N. Houk, J. Am. Chem. Soc. 2015, 137, 2856

4 P. M. Beaujuge and J. M. J. Frechet, J. Am. Chem. Soc. 2011, 133, 20009

5 M. J. Kang, I. Doi, H. Mori, E. Miyazaki, K. Takimiya, M. Ikeda and H. Kuwabara, Adv. Mater., 2011, 23, 1222

6 C. Mitsui, J. Soeda, K. Miwa, H. Tsuji, J. Takeya and E. Nakamura, J. Am. Chem. Soc. 2012, 134, 5448

7 C. Wetzel, E. Brier, A. Vogt, A. Mishra, E. M. Osteritz and P. Bauerle, Angew. Chem. Int. Ed. 2015, 54, 12334

8 H. Xia, D. Q. Liu, X. M. Xu and Q. Miao Chem. Commun., 2013, 49, 4301

9 J. D. Wood, J. L. Jellison, A. D. Finke, L. C. Wang and K. N. Plunkett, J. Am. Chem. Soc. 2012, 134, 15783

10 Z. U. Levi and T. Don Tilley. J. Am. Chem. Soc. 2010, 132, 11012

11 G. E. Rudebusch, A. G. Fix, H. A. Henthorn, C. L. Vonnegut, L. N. Zakharov and M. M. Haley, Chem. Sci., 2014, 5, 3627

12 D. T. Chase, A. G. Fix, S. J. Kang, B. D. Rose, C. D. Weber,Y. Zhong, L. N. Zakharov, M. C. Lonergan, C. Nuckolls and M. M. Haley, J. Am. Chem. Soc. 2012, 134, 10349

13 M. F. Wang, A. R. Mohebbi, Y. M. Sun and F. Wudl, Angew. Chem. Int. Ed. 2012, 51, 6920

14 H. Y. Li, F. S. Kim, G. Q. Ren, E. C. Hollenbeck, S. Subramaniyan and S. A. Jenekhe, Angew. Chem. Int. Ed. 2013, 125, 5623

15 X. Gu, X. M. Xu, H. Y. Li, Z. F. Liu and Q. Miao, J. Am. Chem. Soc., 2015, 137, 16203

16 A. C. Fahrenbach, J. C. Barnes, D. A. Lanfranchi, H. Li, A. Coskun, J. J. Gassensmith, Z. Liu, D. Benitez, A. Trabolsi, W. A. Goddard, M. Elhabiri and J. F. Stoddart, J. Am. Chem. Soc. 2012, 134, 3061

17 H. Zhylitskaya, J. Cybinska, P. Chmielewski, T. Lis and M. Stepien, J. Am. Chem. Soc. 2016, DOI: 10.1021/jacs.6b07826

18 C. C. Ferron, M. Capdevila-Cortada, R. Balster, F. Hartl, W. Niu, M. He, J. J. Novoa, J. T. Lopez Navarrete, V. Hernandez and M. C. Ruiz Delgado, Chem. Eur. J. 2014, 20, 10351.

19 When non-substituted benzo[1,2-b:4,5-b']- dithiophene was used, an insoluble product was obtained. Its high resolution mass spectrum nevertheless proved the successful synthesis of the corresponding FC-PAC.

20 C. C. Ferron. M. C. Ruiz Delgado, V. Hernandez, J. T. Lopez Navarrete, B. Vercelli, G. Zotti, M. C. Cortada, J. J. Novoa, W. Niu, M. He and F. Hartl, Chem. Commun. 2011, 47, 12622

21 The second reduction potential $-1.9 \mathrm{~V}$ is very close to the end of the cathodic potential window of $\mathrm{CH}_{2} \mathrm{Cl}_{2}$, which prevented the measurement of the electronic absorption spectrum of stable $[\mathbf{M} 4]^{2-}$ at this electrode potential.

22 Y. Xiong, J. Tao, R. Wang, X. Lan, X. Yang, D. Wang, H. Wu and H. Li, Adv. Mater., 2016, 28, 5949. 